\title{
BMJ Open Socioeconomic variations in female fertility impairment: a study in a cohort of Portuguese mothers
}

\author{
Sofia Correia, , ${ }^{1,2}$ Teresa Rodrigues, ${ }^{1,2,3}$ Henrique Barros ${ }^{1,2}$
}

To cite: Correia S,

Rodrigues T, Barros $\mathrm{H}$. Socioeconomic variations in female fertility impairment: a study in a cohort of Portuguese mothers. BMJ Open 2014;4:e003985 doi:10.1136/bmjopen-2013003985

- Prepublication history and additional material for this paper is available online. To view these files please visit the journal online (http://dx.doi.org/10.1136/ bmjopen-2013-003985).

Received 9 September 2013 Revised 20 November 2013 Accepted 21 November 2013

CrossMark

\begin{abstract}
${ }^{1}$ Department of Clinical Epidemiology, Predictive Medicine and Public Health, University of Porto Medical School, Porto, Portugal ${ }^{2}$ Institute of Public Health, University of Porto, Porto, Portugal

${ }^{3}$ Department of Gynaecology and Obstetrics, Hospital SaO Joao-EPE, Porto, Portugal
\end{abstract}

Correspondence to Dr Sofia Correia; scorreia@med.up.pt

\section{ABSTRACT}

Objectives: This study aimed to assess the association of socioeconomic conditions with female fertility impairment among women who delivered a live birth.

Design: Cross-sectional analysis.

Setting: Population-based birth cohort (Generation XXI) assembled in 2005/2006 from five public maternity units in Porto Metropolitan Region, Northern Portugal.

Participants: 7472 women aged 18 or more with spontaneous conception and no male diagnosis of infertility were recruited and interviewed immediately after birth with structured questionnaires.

Exposures of interest: Maternal education, occupation and income were recorded as proxy indicators of social conditions.

Outcome: Impaired female fertility, defined as women who had unsuccessfully tried to conceive for over a year.

Data analysis: Multivariate logistic regression models were fitted to estimate the association between each socioeconomic indicator and impaired female fertility, stratified by previous pregnancy experience and adjusted for age, pregnancy planning and behavioural characteristics.

Results: Among primigravidae, $7.7 \%(95 \% \mathrm{Cl} 6.8 \%$ to $8.6 \%$ ) presented impaired fertility and the prevalence was $9.6 \%(95 \% \mathrm{Cl} 8.7 \%$ to $10.6 \%)$ in multigravidae. In crude analysis, we found women with impaired fertility to be older, less educated, more likely to have planned the current pregnancy and to be overweight/obese; they had similar levels of income or occupation. In multivariate models, a significant independent association between educational level and female fertility impairment remained among primigravidae (OR $(95 \% \mathrm{Cl})$ vs $\leq 6$ schooling years: 7-9: 0.85 (0.54 to 1.34 ); 10-12: 0.34 (0.21 to 0.54 ); $>12: 0.24$ ( 0.14 to 0.40$), p_{\text {trend }}<0.001$ ) but not in multigravidae.

Conclusions: This study shows that education might be important in understanding female fertility impairment, particularly among first-time pregnant women. It also points out that the association is not totally explained by other sociodemographic and lifestyle characteristics that have been previously found to be important to disclose this relation.

\section{Strengths and limitations of this study}

- This study used a large sample of truly fertile women allowing the understanding of the different social realities.

- Not restricting the sample to planned pregnancies or to women attending fertility clinics, strengthened its external validity.

- Data on fertility impairment were collected retrospectively after birth and misclassification may have occurred.

\section{INTRODUCTION}

International reviews of the prevalence of fertility impairment, defined as women unable to achieve a clinically recognised pregnancy after attempting for more than 1 year, found that ranges from $7 \%$ to $39 \%$, depending on the reproductive outcome assessed (whether pregnancy or live birth) and the populations included-for example, all women trying to get pregnant for the first time or married women. ${ }^{1-3}$

Women's age, sexually transmitted diseases, polycystic ovary syndrome, endometriosis and pelvic inflammatory disease have been considered the proximal causes of female fertility impairment. ${ }^{4-8}$

Over the recent decades, several countries have shown a decrease in their total fertility rates (in a demographic perspective considering the total number of children per woman). ${ }^{9}$ However, there is no consensus whether it may result from a decline in biological fertility. Some authors report an increase in the ability to conceive explained by better social conditions and less sexually transmitted infections, ${ }^{10} 11$ others a fertility decrease related to women's postponement of childbearing age and adverse lifestyles ${ }^{12}{ }^{13}$ while yet others have found no differences in trends. ${ }^{14}$

Hence, in addition to the pathological factors related to the female reproductive system, socioeconomic circumstances could influence fertility through different pathways. 
More highly educated women are more likely to postpone childbearing to an age when the probability of conception decreases and the probability of early pregnancy loss increases. ${ }^{15} 16$ They are also more likely to plan pregnancy and to be aware of fertility problems, promoting the decision to seek for help. ${ }^{17}$ However, less-educated women are more likely to be overweight, to smoke and to have more risky sexual behaviour which may negatively impact female fertility. ${ }^{18-20}$ Despite the correlation between different dimensions of socioeconomic circumstances, their components may impact fertility by different mechanisms. Income allows easier or faster access to health services, namely infertility clinics and also to material resources as better food or service promoters of better health. ${ }^{21}$ Occupation may also be related to infertility because of labour pressure, working schedules and psychosocial stress or because of the exposure to environmental pollutants known to decrease implantation rates and increase spontaneous abortion. ${ }^{19}$

Aiming at understanding how social circumstances might impact female fertility decline, we designed a cross-sectional analysis of the association between socioeconomic conditions (measured by different proxy indicators) and the occurrence of female fertility impairment in women who had subsequently delivered a live birth.

\section{METHODS}

This study was conducted within Generation XXI, a population-based cohort of 8647 babies and 8495 mothers assembled between April 2005 and August 2006 from five public maternity units in the Porto Metropolitan Area in the North of Portugal. All resident women delivering a live birth with more than 23 gestational weeks were eligible. In all, $70 \%$ of the eligible mothers were consecutively invited (not all eligible mothers were invited due to logistic constraints, namely availability of human resources; in these circumstances, women were invited on a basis of first come, first served) and $8 \%$ of those refused to participate. Participants were interviewed face to face between $24 \mathrm{~h}$ and $72 \mathrm{~h}$ after delivery. Data were collected using a standardised questionnaire on maternal sociodemographics, obstetric and gynaecological history, planning and occurrence of the current pregnancy, prenatal care and lifestyles. ${ }^{22}$ A subgroup of women was recruited in pregnancy when pregnant women went to their first hospital antenatal appointment at two of the included units (up to the 13th gestational week). These interviews were conducted during each trimester and so, most data were collected at different stages compared to the rest of the cohort. ${ }^{23}$ The study was approved by the ethics committee from the University of Porto Medical School/Hospital S. João and all women taking part were required to sign a consent form, designed according to the Declaration of Helsinki.

For the current analysis women aged 18 years or more (8334) were eligible. We excluded 105 women who reported a diagnosis of male infertility in their partner and a further 119 who had non-spontaneous conception, including pregnancies resulting from assisted reproductive technology or after ovulation induction medication. Because of different timings of data collection 280 women recruited during pregnancy and 358 with missing data for fertility status, parity or the exposure variables were also excluded (figure 1).

\section{Socioeconomic measures}

Maternal educational level, occupation and household monthly income were indicators of the socioeconomic circumstances. Educational level was recorded as the number of completed years of education and categorised as $\leq 6,7-9,10-12$ and $>12$. Occupation was recorded using self-reported current job and daily tasks and classified using the National Occupation Classification (1994, revised in 2000), supplementary classified as ISCO-2008. Occupations were further grouped into higher level whitecollar workers (managers, professionals, technicians and associate professionals), lower level white-collar workers (clerical support workers, services and sales workers), skilled blue-collar workers (skilled agricultural, forestry and fishery workers, craft and related trades workers, plant and machine operators) and unskilled blue-collar workers (elementary occupations). ${ }^{24}$ Household monthly income was recorded in $€ 500$ categories and was grouped as $\leq € 1000$; $€ 1001-€ 2000 ;>€ 2000$ and those who said they did not know or who did not want to reply.

\section{Fertility status}

Women were asked whether they had ever tried to conceive for more than a year without success. Those who said they had were classified as having female fertility impairment and were asked how long they had spent attempting to get pregnant. This was categorised as 13-23; 24-35 and >35 months. Women were asked if they had ever sought medical help (advice or treatment) because

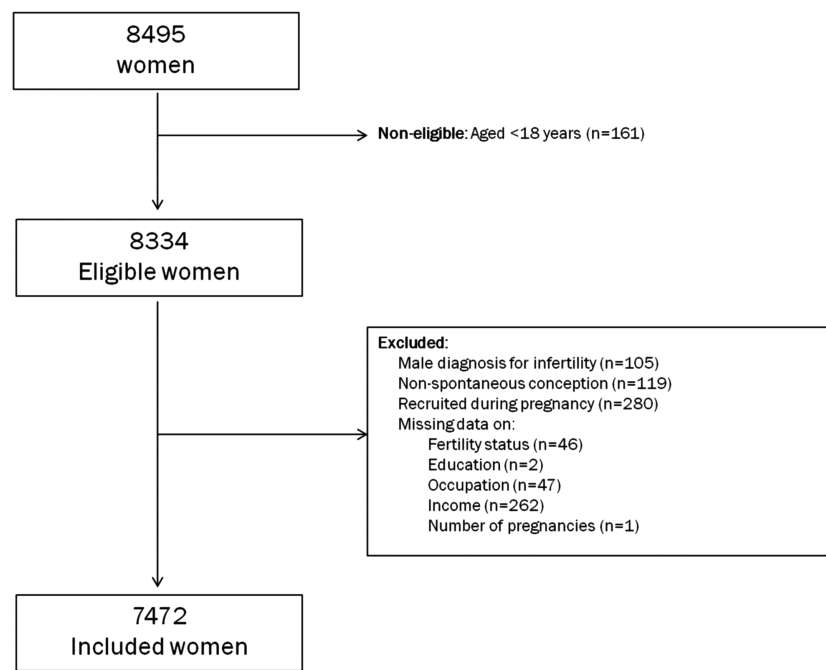

Figure 1 Participants selection. 
they could not get pregnant. Those who had done so reported the medical diagnosis for their delay in conception.

Women were asked if they had planned the current pregnancy and those who answered yes were also asked how long it had taken them to become pregnant. This was grouped into under 6, 6-11, 12-24 and over 24 months.

\section{Covariates}

Women were asked about their age at the time of birth, their marital status, age at menarche, regularity of their menstrual cycle (considered as regular if occurring once a month for around 5 days) and age at first sexual intercourse.

Smoking 3 months before pregnancy was categorised as: never smokers (including occasional smokers), ex-smokers (former smokers who had not smoked during the 3 months before conception), smokers of 114 cigarettes/day and smokers of more than 14 cigarettes/day.

The self-reported pre-pregnancy weight was used to calculate maternal pre-pregnancy body mass index (BMI). Height was measured whenever possible, otherwise data were copied from their citizen identity card. BMI was calculated as 'weight $(\mathrm{kg}) /($ height $\times$ height $)(\mathrm{m})$ ' and grouped as $\leq 24.9 ; 25-29.9 ; \geq 30 \mathrm{~kg} / \mathrm{m}^{2}$.

Data on pregnancy screening tests for infections were retrieved from maternal pregnancy passports (booklet provided to all women; contains the record of check-ups, ultrasounds, tests and medical notes). Women were classified as having an infection if they were positive for syphilis (Venereal Disease Research Laboratory testVDRL), hepatitis B (hepatitis B surface antigen-
HBsAg), hepatitis $\mathrm{C}$ (antibodies against hepatitis $\mathrm{C}$ virus -Anti-HCV) or HIV.

\section{Data analysis}

Women's characteristics were analysed according to the fertility status and compared using $\chi^{2}$ tests. Multivariate logistic regression models were used to calculate OR and their respective $95 \%$ CIs (95\% CI) as measures of the association between each socioeconomic indicator (education, occupation and income) and female fertility impairment, independently of age, pregnancy planning, pre-pregnancy BMI, smoking, age at first sexual intercourse, infection status and age at menarche. The final model includes only the variables that changed the OR by more than $10 \%$.

The number of previous pregnancies modified the effect of education on fertility impairment and so we stratified the analysis by the number of previous pregnancies: primigravidae (first pregnancy) and multigravidae (more than one pregnancy). The possible interaction between age and education was also tested. The analysis was repeated including only women who had not sought medical help or infertility problems. For multigravidae, sensitivity analyses were performed excluding women with no previous successful pregnancy (multigravidae but nulliparous) and those that reported current time-to-pregnancy over 12 months.

\section{RESULTS}

The final sample comprised 7472 women who were similar to the excluded participants in terms of socioeconomic indicators and BMI but were more likely to be younger (29 vs 30 years, $\mathrm{p}<0.001)$ and to be smokers (26\% vs $20 \%, \mathrm{p}<0.001$; table 1$)$.

Table 1 Characteristics of included and excluded women

\begin{tabular}{|c|c|c|c|c|c|c|c|c|}
\hline & $\mathbf{N}$ & $\begin{array}{l}\text { Mean } \\
\text { age (SD) }\end{array}$ & $\begin{array}{l}\text { Mean } \\
\text { education } \\
\text { (SD) }\end{array}$ & $\begin{array}{l}\text { Living with } \\
\text { partner, } \\
\text { n (\%) }\end{array}$ & $\begin{array}{l}\text { Monthly } \\
\text { income > } \\
€ 2000, \mathrm{n}(\%)\end{array}$ & $\begin{array}{l}\text { Blue-collar } \\
\text { occupation, } \\
\text { n (\%) }\end{array}$ & $\begin{array}{l}\text { Mean } \\
\text { BMI (SD) }\end{array}$ & $\begin{array}{l}\text { Smokerst, } \\
\text { n (\%) }\end{array}$ \\
\hline \multicolumn{9}{|l|}{ Eligible } \\
\hline Included & 7472 & $29.1(5.4)$ & $10.5(4.2)$ & 7040 (94.5) & 1062 (15.7) & $682(9.1)$ & $23.9(4.3)$ & 1952 (26.4) \\
\hline Excluded & 862 & $30.0(5.3)$ & $10.6(4.2)$ & $787(94.1)$ & $63(13.2)$ & $62(7.9)$ & $23.8(4.3)$ & $156(20.3)$ \\
\hline p Values $\ddagger$ & & $p<0.001$ & $p=0.670$ & $p=0.691$ & $p=0.146$ & $p=0.253$ & $p=0.636$ & $p<0.001$ \\
\hline $\begin{array}{l}\text { Male } \\
\text { infertility }\end{array}$ & 105 & $30.9(4.3)$ & $11.3(4.0)$ & 99.0 & 20.2 & 6.7 & $23.9(4.3)$ & 20.0 \\
\hline $\begin{array}{l}\text { Non- } \\
\text { spontaneous } \\
\text { conception }\end{array}$ & 119 & $31.5(4.1)$ & $12.2(4.3)$ & 99.2 & 27.4 & 3.4 & $23.6(3.8)$ & 13.0 \\
\hline $\begin{array}{l}\text { Recruited } \\
\text { during } \\
\text { pregnancy }\end{array}$ & 280 & $29.5(5.8)$ & $9.2(3.6)$ & 89.9 & 4.9 & 13.1 & $24.7(4.8)$ & 30.0 \\
\hline Missing data* & 358 & $29.7(5.4)$ & $10.9(4.4)$ & 94.4 & 10.3 & 5.2 & $23.3(4.1)$ & 15.2 \\
\hline \multicolumn{9}{|l|}{ Non-eligible } \\
\hline Age $<18$ & 161 & $16.4(0.9)$ & $7.1(2.1)$ & 51.6 & 2.6 & 5.3 & $21.8(3.0)$ & 40.4 \\
\hline
\end{tabular}


Among primigravidae, $7.7 \%$ (95\% CI 6.8 to 8.6 ) had taken more than 1 year to conceive. The prevalence was 9.6\% (95\% CI 8.7 to 10.6 ) in those with a previous pregnancy. Within fertility impaired women, 39\% (86/219) of primigravidae and 35\% (123/348) of multigravidae had taken 3 years or more to get pregnant. Although not statistically significant, less educated women were more likely to report more than 3 years of involuntary childlessness ( $\leq 6$ vs $>12$ schooling years: $44.5 \%$ vs $31.9 \%)$. Seven per cent of women $(517 / 7402)$ had sought medical help because they could not get pregnant and $71 \%$ reported a clinical diagnosis. Among impaired women, seeking for help was more frequent in the more educated $(69.4 \%$ in women with $\geq 12$ years of education vs $58.2 \%$ in women with $\leq 6$ years), but no differences were found in fertile women. More detailed data on seeking behaviour and clinical diagnosis may be found in online supplementary table S1.

As described in table 2, women trying to conceive for more than 1 year were older ( $\geq 40$ years: $5.6 \%$ vs $2.3 \%$, $\mathrm{p}<0.001$ ), less educated ( $>12$ schooling years: $19 \%$ vs $25 \%, \mathrm{p}=0.001)$ and less likely to be single $(2.8 \%$ vs $5.8 \%$, $\mathrm{p}<0.001)$ but similar in terms of household monthly income ( $€ € 2000: 14.9 \%$ vs $15.8 \%, p=0.748)$, occupation (blue-collar: $25 \%$ vs $22 \%, \mathrm{p}=0.178$ ) or employment status (employed: $74 \%$ vs $73 \%, \mathrm{p}=0.070$ ).

Women with fertility impairment were less likely to report having regular menstrual cycles, were more likely to have had the onset of menarche before 12 years or over 13 years of age and were more likely to have planned the current pregnancy. Among multigravidae, they reported more frequently to have had a previous adverse pregnancy outcome. Smoking habits were similar according to the fertility status. Overweight and obesity were found in $41 \%$ of women with fertility impairment (and in $29.8 \%$ of fertile women, $\mathrm{p}<0.001$ ) but no statistically significant differences were found according to the self-perception of health status.

Low-educated women $(<6$ years) were more likely than more educated ( $>12$ years) to be overweight or obese ( $45 \%$ vs $20 \%)$ and to report early age at sexual initiation (<16 years: $12 \%$ vs $2 \%)$.

From figure 2 it can be observed that, among primigravidae, higher education level was associated with a decrease in female fertility impairment, independently of other demographic and behavioural characteristics. Compared to those with six or less years of education, having 7-9, 10-12 and more than 12 years of formal education was associated with lower odds of having infertility (OR $(95 \% \mathrm{CI})$ vs $\leq 6$ years: $7-9$ years: 0.85 (0.54 to 1.34$)$; $10-12$ years: $0.34 \quad(0.21$ to 0.54$)$; $>12$ years: 0.24 ( 0.14 to 0.40$)$, $\left.\mathrm{p}_{\text {trend }}<0.001\right)$. The results were accentuated in the analysis restricted to women who did not seek medical help (7-9 years: $0.54(0.27$ to $1.09)$; $10-12$ years: 0.18 (0.08 to 0.40$)$; >12 years: 0.11 (0.04 to 0.29$\left.), \mathrm{p}_{\text {trend }}<0.001\right)$. No significant association was found in the interaction between age and education.
Among multigravidae, no statistically significant differences were found. However, the association between education and female fertility impairment seems to assume a U shape (7-9 years: 1.26 (0.88 to 1.84$)$; 10 12 years: 1.42 (0.99 to 2.05 ); >12 years: 1.00 (0.66 to $1.52)$; figure 2). Similar results were observed when considering only multigravidae with a previous live birth (79: 1.20 (0.79 to 1.82 ); $10-12$ : 1.45 (0.97 to 2.18 ); >12: $1.19(0.75$ to 1.90$)$ ) or within those for whom the current pregnancy was achieved in $\leq 12$ months (7-9: 1.68 ( 0.83 to 3.41 ); $10-12: 1.26$ (0.60 to 2.64 ); $>12: 1.76$ (0.87 to 3.56$))$.

Income and occupation were associated with infertility within primigravidae but no association was found for multigravidae (table 3). More affluent primigravidae and women in higher level white-collar occupations had significantly lower odds of infertility. The differences were attenuated and no longer significant after adjustment for years of education which remained significantly associated with fertility with similar point estimates.

\section{DISCUSSION}

Among primigravidae who had recently delivered a live birth we found that higher education was associated with a decrease in female fertility impairment independently of age and other behavioural factors, but no other socioeconomic indicator was related. In women who had already experienced a previous pregnancy, neither educational level nor other social indicators were associated with this condition.

The association between education and fertility impairment was previously described in other large population-based European studies among primiparous women, ${ }^{11} 18$ and was explained by the effect of education on decreasing the exposure to adverse lifestyles, risky sexual behaviour and body weight. On the contrary, an increase in infertility with increasing education was also found in another study in the UK although the authors argue that it reflects the increasing recognition of the fertility problem among this group of women and does not result from a biological reduction in the ability to conceive. $^{25}$ Other studies in Denmark ${ }^{26}$ and Scotland ${ }^{14}$ found no relation between social class/education and infertility. These different results may reflect the huge geographical variations of socioinequalities in health ${ }^{27}$ besides differences in the definitions and in the socioeconomic indicators used.

Our results were only partly explained by variations in women's behaviours. It is known, and was also previously found for this cohort, that smoking and obesity are more frequent in socially deprived women. ${ }^{22}$ Yet, our results may reflect reverse causation because women with impaired fertility might have been advised to adopt healthier lifestyles. However, the proportion of women seeking medical help because of infertility problems was small $(7 \%)$ and the results were even of greater magnitude when excluding these women. 
Table 2 Women's characteristics by fertility impairment status

\begin{tabular}{|c|c|c|c|}
\hline & \multicolumn{3}{|c|}{ Female fertility impairment } \\
\hline & $\begin{array}{l}\text { No } \\
(n=6820)\end{array}$ & $\begin{array}{l}\text { Yes } \\
(n=652)\end{array}$ & p Value \\
\hline \multicolumn{4}{|l|}{ Age (years) } \\
\hline $18-24$ & $1490(21.8)$ & 87 (11.9) & \\
\hline 25-29 & $2101(30.8)$ & $189(25.8)$ & \\
\hline $30-34$ & $2173(31.9)$ & 265 (36.2) & \\
\hline 35-39 & 897 (13.2) & 149 (20.4) & \\
\hline$\geq 40$ & $159(2.3)$ & $41(5.6)$ & $<0.001$ \\
\hline \multicolumn{4}{|l|}{ Education (years) } \\
\hline$\leq 6$ & $1539(22.6)$ & $182(27.9)$ & \\
\hline $7-9$ & $1745(25.6)$ & $179(27.4)$ & \\
\hline $10-12$ & $1850(27.1)$ & $167(25.6)$ & \\
\hline$>12$ & $1686(24.7)$ & $124(19.0)$ & 0.001 \\
\hline Single women & $394(5.8)$ & $18(2.8)$ & 0.001 \\
\hline \multicolumn{4}{|l|}{ Monthly income $(€)$} \\
\hline$\leq 1000$ & $2456(40.0)$ & $253(41.3)$ & \\
\hline $1001-2000$ & $2711(44.2)$ & $268(43.8)$ & \\
\hline$>2000$ & $971(15.8)$ & $91(14.9)$ & 0.748 \\
\hline Not known/no answer & 10.0 & 6.1 & \\
\hline Occupation & & & 0.178 \\
\hline Higher level white-collar & 1607 (23.6) & $136(20.9)$ & \\
\hline Lower level white-collar & $3281(48.1)$ & $310(47.6)$ & \\
\hline Skilled blue-collar & 876 (12.8) & $104(16.0)$ & \\
\hline Unskilled blue-collar & $622(9.1)$ & $60(9.2)$ & \\
\hline No occupation & $434(6.4)$ & $42(6.4)$ & \\
\hline \multicolumn{4}{|l|}{ Employment status } \\
\hline Employed & $4942(72.6)$ & $471(74.2)$ & \\
\hline Unemployed & 1316 (19.3) & $131(20.1)$ & \\
\hline Housewife & $405(6.0)$ & $46(7.1)$ & \\
\hline Student & 127 (1.9) & $4(0.6)$ & \\
\hline Other & $19(0.3)$ & $0(0.0)$ & 0.074 \\
\hline Planned pregnancy & $4482(65.8)$ & $531(81.4)$ & $<0.001$ \\
\hline \multicolumn{4}{|l|}{ Previous pregnancies } \\
\hline None & 3227 (47.3) & $268(41.1)$ & \\
\hline One or more & $3593(52.7)$ & $384(58.9)$ & 0.002 \\
\hline From the same father & 2901 (81.8) & $318(84.6)$ & 0.177 \\
\hline With live birth & $2990(84.7)$ & $302(80.1)$ & 0.020 \\
\hline \multicolumn{4}{|l|}{ Age at menarche (years) } \\
\hline$\leq 11$ & 1708 (25.3) & $181(28.0)$ & \\
\hline 12 & $2049(30.4)$ & $162(25.1)$ & \\
\hline 13 & $1520(22.5)$ & $149(23.1)$ & \\
\hline$>13$ & $1468(21.8)$ & $154(23.8)$ & 0.038 \\
\hline \multicolumn{4}{|c|}{ Age at first sexual intercourse (years) } \\
\hline$\leq 15$ & $344(7.4)$ & $36(8.6)$ & \\
\hline $16-17$ & $1239(26.6)$ & $115(27.3)$ & \\
\hline $18-19$ & $1630(35.0)$ & $129(30.6)$ & \\
\hline $20-24$ & $1152(24.8)$ & $117(27.8)$ & \\
\hline$\geq 25$ & $286(6.2)$ & $24(5.7)$ & 0.349 \\
\hline Regular menstrual cycles & $5618(83.4)$ & $417(64.6)$ & $<0.001$ \\
\hline \multicolumn{4}{|c|}{ Self-reported health status before pregnancy } \\
\hline Poorer or fair & $990(14.6)$ & $101(15.6)$ & \\
\hline Good & $3666(54.1)$ & $362(56.0)$ & \\
\hline Very good & $930(13.7)$ & $80(12.4)$ & \\
\hline Excellent & $1194(17.6)$ & $104(16.1)$ & 0.496 \\
\hline \multicolumn{4}{|c|}{ Pre-pregnancy body mass index $\left(\mathrm{kg} / \mathrm{m}^{2}\right)$} \\
\hline$<180$ & $267(4.0)$ & $16(2.5)$ & \\
\hline $180-24.9$ & 4391 (66.2) & 361 (56.6) & \\
\hline 250-29.9 & 1405 (21.2) & $175(27.4)$ & \\
\hline$\geq 300$ & $574(8.6)$ & $86(13.5)$ & $<0.001$ \\
\hline
\end{tabular}


Table 2 Continued

\begin{tabular}{|c|c|c|c|}
\hline & \multicolumn{3}{|c|}{ Female fertility impairment } \\
\hline & $\begin{array}{l}\text { No } \\
(n=6820)\end{array}$ & $\begin{array}{l}\text { Yes } \\
(n=652)\end{array}$ & p Value \\
\hline \multicolumn{4}{|c|}{ Smoking status 3 months before pregnancy } \\
\hline Never-smoker & $4212(62.3)$ & $400(61.7)$ & \\
\hline Ex-smoker & 768 (11.4) & $72(11.1)$ & \\
\hline 1-14 cigarettes/day & $952(14.1)$ & $96(14.8)$ & \\
\hline \multirow[t]{2}{*}{$\geq 15$ cigarettes/day } & 824 (12.2) & $80(12.4)$ & 0.960 \\
\hline & $\mathrm{n}=5280$ & $\mathrm{n}=507$ & \\
\hline Infection* & $83(1.6)$ & $9(1.8)$ & 0.727 \\
\hline
\end{tabular}

The (non)-observed attenuation may be underestimated because the study recruitment strategy was on live born children. In fact, the socioeconomic circumstances may affect the different stages of conception. Obesity and smoking status could be associated with delays in conception and also with early pregnancy loss. 192829

It is known that early age at the first sexual intercourse may be associated with a higher risk of infertility because of the higher probability of sexually transmitted diseases. ${ }^{30}$ Early age at the first sexual intercourse is also more frequent among least affluent women. In our study it did not entirely explain the association between education and fertility impairment, probably because this indicator may not have fully captured sexually transmitted infections. Similar was the situation when controlling for infection status although we do not have data for other infections such as Chlamydia trachomatis or Neisseria gonorrhoeae that are known to be associated with infertility. ${ }^{7}$

Therefore, we cannot exclude the possibility that years of education were associated with decreased ability to conceive by means of other biological mechanisms as well as through different social attitudes towards motherhood. Also, maternal age could modify the association between education and fertility impairment assuming that (1) fertility does not decline steadily with age and (2) other pathological conditions may contribute to female infertility distinctively across women's reproductive life. ${ }^{13}$ We had not found a statistical significant interaction between age and education but the effect of education seemed to be attenuated with increasing age (data not shown). This may be a reason for the null effect found among multigravidae (mean age 31 years vs 27 in primigravidae). Besides that, if education and the pressure of the labour market lead to the postponement of childbearing, it is also possible that better social conditions may increase the likelihood of having more than one child. ${ }^{9}$ We could not know if fertility impairment had occurred in more than one pregnancy. Joffe and colleagues, in a multicentre analysis found that couples experiencing a previous history of infertility may be more likely to experience it in a subsequent pregnancy. However, other behaviours might also influence the reproductive history in the sense of not having another child. $^{31}$ These unmeasured characteristics hold back a clear understanding of which factors may have more impact on fertility impairment in women with a previous child.
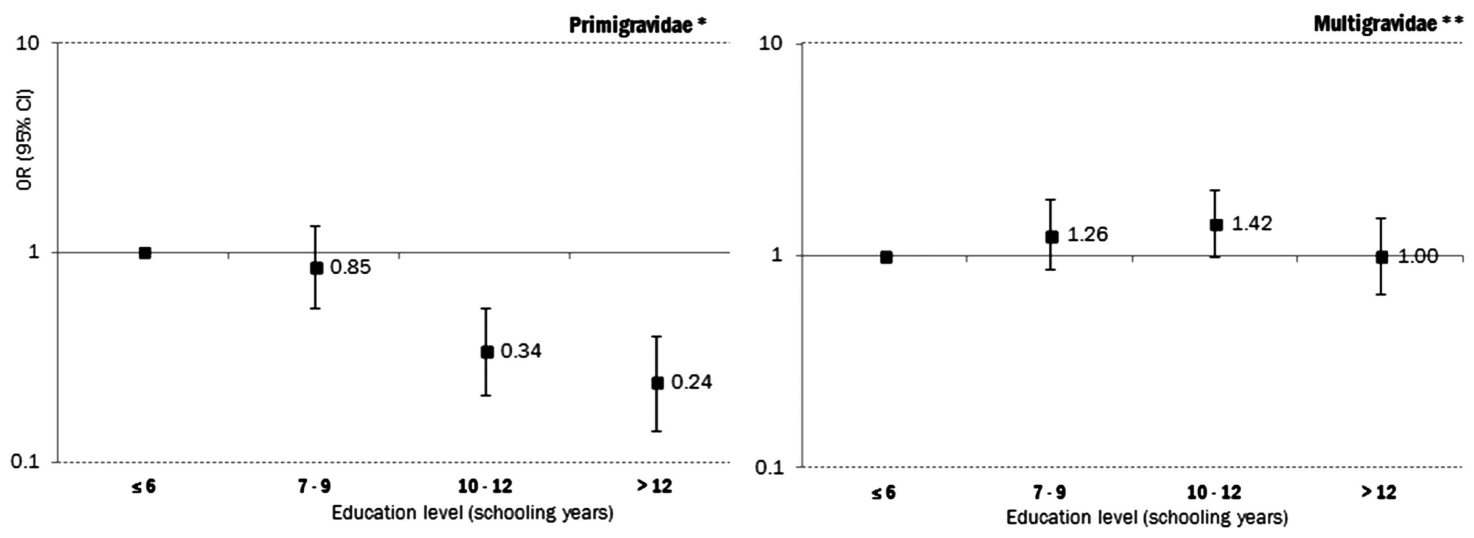

Figure 2 Association between educational level and female fertility impairment, stratified by the occurrence of a previous pregnancy. * Primigravidae: OR adjusted for maternal age, pregnancy planning and age at first sexual intercourse; ${ }^{* *}$ Multigravidae: OR adjusted for maternal age, pregnancy planning, age at first sexual intercourse and body mass index. 
Table 3 Association between each socioeconomic indicator and female fertility impairment, stratified by the number of previous pregnancies

\begin{tabular}{|c|c|c|}
\hline & \multicolumn{2}{|c|}{ Female fertility impairment } \\
\hline & \multicolumn{2}{|c|}{ OR (95\% Cl) } \\
\hline & Model 1* & Model 1+maternal education \\
\hline \multicolumn{3}{|l|}{ Primigravidae $(n=2375)$} \\
\hline \multicolumn{3}{|l|}{ Monthly income $(€)$} \\
\hline$\leq 1000$ & 1 & 1 \\
\hline $1001-2000$ & $0.62(0.43$ to 0.89$)$ & $0.93(0.64$ to 1.37$)$ \\
\hline$>2000$ & $0.47(0.27$ to 0.81$)$ & $1.02(0.54$ to 1.91$)$ \\
\hline Not known/no answer & $0.60(0.31$ to 1.18$)$ & $0.70(0.36$ to 1.38$)$ \\
\hline \multicolumn{3}{|l|}{ Occupation } \\
\hline Unskilled blue-collar & 1 & 1 \\
\hline Skilled blue-collar & $0.93(0.52$ to 1.68$)$ & $0.81(0.44$ to 1.47$)$ \\
\hline Lower level white-collar & $0.49(0.30$ to 0.80$)$ & $0.69(0.41$ to 1.15$)$ \\
\hline \multirow[t]{2}{*}{ Higher level white-collar } & 0.32 (0.18 to 0.57$)$ & $0.86(0.41$ to 1.79$)$ \\
\hline & Model 2† & Model 2+maternal education \\
\hline \multicolumn{3}{|l|}{ Multigravidae $(\mathrm{n}=2582)$} \\
\hline \multicolumn{3}{|l|}{ Monthly income $(€)$} \\
\hline$\leq 1000$ & 1 & 1 \\
\hline $1001-2000$ & $1.11(0.81$ to 1.51$)$ & $1.05(0.75$ to 1.46$)$ \\
\hline$>2000$ & 0.94 (0.61 to 1.44$)$ & 0.97 (0.59 to 1.60$)$ \\
\hline Not known/no answer & 0.61 (0.33 to 1.12$)$ & $0.59(0.32$ to 1.10$)$ \\
\hline \multicolumn{3}{|l|}{ Occupation } \\
\hline Unskilled blue-collar & 1 & 1 \\
\hline Skilled blue-collar & 0.94 (0.58 to 1.53$)$ & 0.94 (0.58 to 1.52$)$ \\
\hline Lower level white-collar & $1.08(0.73$ to 1.62$)$ & $0.98(0.64$ to 1.49$)$ \\
\hline Higher level white-collar & $1.00(0.63$ to 1.61$)$ & 1.08 (0.59 to 2.00$)$ \\
\hline
\end{tabular}

Educational level was the only socioeconomic indicator found to be significantly associated with female fertility impairment. Depending on the setting, each indicator embodies distinct dimensions of social status and these may differ in their effects on individuals' health. In young adulthood, education seems to be the factor most strongly associated with health ${ }^{21}$ as it happened in our sample. Although occupation and income were also associated with impaired female fertility, the estimates were no longer significant when controlling for education. However, these social dimensions seem to be highly correlated and the models may be overadjusted. $^{32}$ Also, some occupations may be associated with environmental exposures related to fertility impairment but we were unable to identify these. ${ }^{33}$

This study used a large population-based sample of mothers who delivered a live birth. Sampling only truly fertile women reduced bias as it excluded sterile women who will never be able to conceive and for whom factors leading to female fertility impairment may be different. ${ }^{7}$ It should be borne in mind that male reproductive impairments are among the possible causes of the current trends in fertility. ${ }^{34}$ We have excluded participants whose partners had a clinically recognised male cause of infertility but we cannot completely rule out male factors for infertility. Only $63 \%$ of women with impaired fertility sought medical help and among these, a clinical diagnosis for infertility was provided for $71 \%$ of women. Therefore, we acknowledge that we might not have totally dissociated the women causes from male or even the couples' causes along with the effects of shared risk factors. Studies show that the risk of infertility is higher if both partners present obesity ${ }^{35}$ and if both are older. $^{36}$ For a subgroup of primigravidae $(n=813)$ for whom we have data from the father at the moment of birth (self-administered questionnaires) we conducted the same analysis adjusting for the shared overweight/ obesity and age over 35 years: the relation between education and infertility did not significantly change (data not shown). We asked women about delay in conception ever in their life. Because of that, it is possible that apparent fertility impairment was related with previous partners male infertility. But the proportion of previous pregnancies from the same father did not differ between the groups and is less likely to have influenced our results.

This study was not restricted to planned pregnancies or to women attending fertility clinics, strengthening its external validity. Inequalities in seeking help for infertility treatment have been observed elsewhere but are not universal. ${ }^{25} 37$ More educated women tend to look for 
infertility treatment sooner, achieving earlier pregnancies and with higher probability of success, possibly resulting in a misclassification of their fertility status. Although we have found this educational pattern among women with fertility impairment, it was not observed in fertile women. Consequently, misclassification is unlikely to have occurred. On the contrary, less educated impaired women might have not sought for treatment and, if they had not achieved a successful pregnancy, they would not have been included in this study. If they had, this would have increased the differences that we found.

Because of different timings of data collection, we have excluded a subgroup of women recruited during pregnancy. We found these women to be less educated than those included in the current analysis. However, assuming that we have correctly estimated the association between education and fertility impairment, the exclusion of this group decreased the power of the current study to detect real differences and did not bias the results.

Female fertility impairment was collected after birth and misclassification may have occurred. However, if misclassification occurred and if it was differential we expect less educated women to be more likely to ignore/under-report their fertility status. ${ }^{38}$ If so, even greater socioeconomic gaps would be observed.

This study shows that social circumstances, particularly education, might be important in understanding patterns of fertility impairment. Their impact seems to depend on the previous reproductive experience. Among first-time pregnant women, infertility decreased with increasing education. This relation was not totally explained by other sociodemographic and lifestyle characteristics that have been previously found to be important to disclose this relation.

Acknowledgements The authors gratefully acknowledge Alison Macfarlane, City University London, for her contribution and kindness. The authors acknowledge the families enrolled in Generation XXI for their generosity, all members of the research team for their enthusiasm and perseverance and the participating hospitals and their staff for their help and support.

Contributors SC was responsible for the collection, analysis and interpretation of data and for the first draft of the manuscript. TR revised the manuscript critically for important intellectual content; HB was responsible for the cohort study design, study concept and interpretation of data and revised the manuscript critically for important intellectual content. All authors approved the final version of the manuscript.

Funding This project was funded by Programa Operacional de Saúde-Saúde XXI, Quadro Comunitário de Apoio III and by Administração Regional de Saúde Norte (Regional Department of Ministry of Health). This work was supported by the Portuguese Foundation for Science and Technology (grant SFRH/BD/66159/2009 to Correia S). Sponsors were not involved in the study design; in the collection, analysis and interpretation data; in the writing of the report and in the decision to submit the article for publication.

Competing interests None.

Patient consent Obtained.

Provenance and peer review Not commissioned; externally peer reviewed.

Data sharing statement Extra data is available by emailing Sofia Correia (scorreia@med.up.pt).
Open Access This is an Open Access article distributed in accordance with the Creative Commons Attribution Non Commercial (CC BY-NC 3.0) license, which permits others to distribute, remix, adapt, build upon this work noncommercially, and license their derivative works on different terms, provided the original work is properly cited and the use is non-commercial. See: http:// creativecommons.org/licenses/by-nc/3.0/

\section{REFERENCES}

1. Schmidt L. Infertility and assisted reproduction in Denmark Epidemiology and psychosocial consequences. Dan Med Bull 2006;53:390-417.

2. Gurunath S, Pandian Z, Anderson RA, et al. Defining infertility-a systematic review of prevalence studies. Hum Reprod Update 2011;17:575-88.

3. Gnoth C, Godehardt E, Frank-Herrmann P, et al. Definition and prevalence of subfertility and infertility. Hum Reprod 2005;20:1144-7.

4. Baecher-Lind LE, Miller WC, Wilcox AJ. Infectious disease and reproductive health: a review. Obstet Gynecol Surv 2010;65:53-65.

5. Frank O, Bianchi PG, Campana A. The end of fertility: age, fecundity and fecundability in women. J Biosoc Sci 1994;26:349-68.

6. Halis G, Arici A. Endometriosis and inflammation in infertility. Ann N Y Acad Sci 2004;1034:300-15.

7. Wilcox AJ. Fertility and pregnancy: an epidemiologic perspective. 1st edn. New York: Oxford University Press, 2010.

8. Younis JS. Ovarian aging and implications for fertility female health. Minerva Endocrinol 2012;37:41-57.

9. ESHRE CWG. Europe the continent with the lowest fertility. Hum Reprod Update 2010;16:590-602.

10. Scheike TH, Rylander L, Carstensen L, et al. Time trends in human fecundability in Sweden. Epidemiology 2008;19:191-6.

11. Akre O, Cnattingius S, Bergstrom R, et al. Human fertility does not decline: evidence from Sweden. Fertil Steril 1999;71:1066-9.

12. Rostad B, Schmidt L, Sundby J, et al. Has fertility declined from mid-1990s to mid-2000s? Acta Obstet Gynecol Scand 2013;92:1284-9.

13. Broekmans FJ, Knauff EA, te Velde ER, et al. Female reproductive ageing: current knowledge and future trends. Trends Endocrinol Metab 2007;18:58-65.

14. Bhattacharya S, Porter M, Amalraj E, et al. The epidemiology of infertility in the North East of Scotland. Hum Reprod 2009;24:3096-107.

15. te Velde ER, Pearson PL. The variability of female reproductive ageing. Hum Reprod Update 2002;8:141-54.

16. ESHRE CWG Social determinants of human reproduction. Hum Reprod 2001;16:1518-26.

17. Morris BA, Egan JF, Fang YM, et al. The relationship between utilization of prenatal care and Down syndrome live births. J Matern Fetal Neonatal Med 2007;20:307-11.

18. Bolumar $\mathrm{F}$, Olsen J, Rebagliato $\mathrm{M}$, et al. Body mass index and delayed conception: a European Multicenter Study on Infertility and Subfecundity. Am J Epidemiol 2000;151:1072-9.

19. Homan GF, Davies M, Norman R. The impact of lifestyle factors on reproductive performance in the general population and those undergoing infertility treatment: a review. Hum Reprod Update 2007;13:209-23.

20. Kelly-Weeder S, Cox CL. The impact of lifestyle risk factors on female infertility. Women Health 2006;44:1-23.

21. Galobardes B, Shaw M, Lawlor DA, et al. Indicators of socioeconomic position (part 1). J Epidemiol Community Health 2006;60:7-12.

22. Alves E, Correia S, Barros $\mathrm{H}$, et al. Prevalence of self-reported cardiovascular risk factors in Portuguese women: a survey after delivery. Int J Public Health 2012;57:837-47.

23. Pinto $\mathrm{E}$, Severo $\mathrm{M}$, Correia $\mathrm{S}$, et al. Validity and reproducibility of a semi-quantitative food frequency questionnaire for use among Portuguese pregnant women. Matern Child Nutr 2010;6:105-19.

24. IEFP. Classificação Nacional de Profissões, versão 19942001. Instituto do Emprego e Formacao Profissional. http://www.iefp.pt/ formacao/CNP/Paginas/CNP.aspx

25. Morris M, Oakley L, Maconochie N, et al. An investigation of social inequalities in help-seeking and use of health services for fertility problems in a population-based sample of UK women. Hum Fertil (Camb) 2011;14:16-22

26. Schmidt L, Munster K, Helm P. Infertility and the seeking of infertility treatment in a representative population. Br J Obstet Gynaecol 1995;102:978-84.

27. Wilkinson RG, Pickett K. The spirit level: why greater equality makes societies stronger. New York: Bloomsbury Press, 2010. 
28. Jungheim ES, Moley KH. Current knowledge of obesity's effects in the pre- and periconceptional periods and avenues for future research. Am J Obstet Gynecol 2010;203: $525-30$.

29. Practice Committee of American Society for Reproductive Medicine. Smoking and infertility. Fertil Steril 2008;90:S254-9.

30. Sandfort TG, Orr M, Hirsch JS, et al. Long-term health correlates of timing of sexual debut: results from a national US study. Am J Public Health 2008;98:155-61.

31. Joffe M, Key J, Best N, et al. The role of biological fertility in predicting family size. Hum Reprod 2009;24:1999-2006.

32. Schisterman EF, Cole SR, Platt RW. Overadjustment bias and unnecessary adjustment in epidemiologic studies. Epidemiology 2009;20:488-95.
33. Caserta D, Mantovani A, Marci R, et al. Environment and women's reproductive health. Hum Reprod Update 2011;17:418-33.

34. Joffe M. What has happened to human fertility? Hum Reprod 2010;25:295-307.

35. Ramlau-Hansen $\mathrm{CH}$, Thulstrup AM, Nohr EA, et al. Subfecundity in overweight and obese couples. Hum Reprod 2007;22:1634-7.

36. de La Rochebrochard E, Thonneau P. Paternal age >or $=40$ years: an important risk factor for infertility. Am J Obstet Gynecol 2003;189:901-5.

37. Smith JF, Eisenberg ML, Glidden D, et al. Socioeconomic disparities in the use and success of fertility treatments: analysis of data from a prospective cohort in the United States. Fertil Steril 2011;96:95-101.

38. White L, McQuillan J, Greil AL, et al. Infertility: testing a helpseeking model. Soc Sci Med 2006;62:1031-41. 